\title{
GANGRENOUS CHOLECYSTITIS: A SURGICAL COMPLICATION OF TYPHOID FEVER IN A CHILD.
}

\author{
Vivian Akello ${ }^{1}$, Denis Bitamazire ${ }^{2}$, Joel Wandabwa ${ }^{2}$, and Robinson Ssebuufu ${ }^{1}$ \\ ${ }^{1}$ Kampala International University - Western Campus \\ ${ }^{2}$ Hoima Regional Referral Hospital
}

May 7, 2020

\begin{abstract}
The occurrence of gangrenous cholecystitis as a complication of typhoid fever is rare. This is a case study of a 7 year old that presented with fever and abdominal pain and later developed abdominal distension. She was later diagnosed with a gangrenous cholecystitis and gall bladder empyema.
\end{abstract}

\section{Keywords}

Gangrenous, Typhoid, Uganda, Cholecystitis

\section{Key Clinical Message}

Typhoid gangrenous cholecystitis is uncommon. Therefore early suspicion and diagnosis is difficult especially in resource limited setting. This article therefore illustrates the challenges and outcomes of managing a child.

\section{Introduction}

Typhoid fever is endemic in the tropics, however the prevalence is difficult to estimate since many febrile illnesses like malaria present similarly[1]. Humans are the only natural host and reservoir of Salmonella Typhi (S Typhi) and it is transmitted by the faecal oral route[1]. In endemic areas like Uganda, it is common in the age group of 5 to 19 years, predominately in children due possibly to their immature immune system[2]. Gangrenous cholecystitis is rare sequelae of acalculous cholecystitis occurring in patients with typhoid fever. We present a case of a complicated typhoid fever in a child.

\section{Case Report}

N.T a seven year old girl presented to Hoima Regional Referral Hospital located in North Western Uganda as a referral from a district hospital following five days hospitalisation and treatment for malaria and septicaemia with antimalarial and antibiotics. She had been unwell for 13 days prior to admission with high grade fevers and abdominal pain. She had recently developed abdominal distension in the last two days. She had no history of yellowing of eyes. She reports episodes of loose motions and no constipation. Also her appetite was poor and the attendant reports she had lost some weight.

On examination she was febrile (38 degree Centigrade), mildly wasted, had no jaundice and was not dehydrated. On abdominal examination, the abdomen was moderately distended, she had generalised tenderness with rebound tenderness. Bowel sounds were reduced. A diagnosis of peritonitis was made and a laparotomy was scheduled. Chest Xray done was normal done was normal, complete blood count done showed leucocytosis and anaemia $(8.0 \mathrm{~g} / \mathrm{dl})$ and Widal test was positive. 
At the laparotomy, we found oedematous, thickened bowel that was matted with purulent ascites of about $200 \mathrm{mls}$, we found no gut perforation. We also found omentum adherent to the surface of the liver and a gangrenous gallbladder and a small gall bladder empyema of about $30 \mathrm{mls}$ of purulent fluid. We had difficulty dissecting the Calots triangle due to adhesions and necrotic gall bladder wall and decided to do a subtotal cholecystectomy with non-closure of the cystic duct. We left a sub hepatic and pelvic drain. On the second post-operative day the child developed a bile leak which was about $100 \mathrm{mls}$ per day in the early days and subsequently decreased. This we managed conservatively and were able to remove the sub hepatic drain 10 days later after which we discharged the child.

\section{Discussion}

Gangrenous gall bladder following S. Typhi or in association with S Typhi is a rare occurrence in children. Also rare is the occurrence of a non perforative peritonitis. Complicated typhoid fever is seen in about $10 \%$ to $15 \%$ of children mainly during the second and third week of illness[3]. Ileal perforation is the commonest complication of typhoid managed surgically[4]. Gallbladder infections are fairly common with Salmonellae being isolated from gallbladder of either chronic or acute disease states[5]. However the diagnosis becomes apparent only when features of acalculous cholecystitis or gallbladder perforation develop in acute infections. [5].

Diagnosis of gall bladder disease in typhoid patients still remains elusive even in endemic areas leading to delays in patient management[6].Gallbladder disease was not suspected in this patient and was initially booked for theatre to explore the cause of the peritonitis. And a chance diagnosis of gallbladder gangrene and empyema made at laparotomy. An ultrasound scan would have enabled diagnosis. Sonographic findings of thickened gall bladder wall occurring with thickened bowel wall especially ileum and caecum and multiple mesenteric nodes is diagnostic of typhoid fever in endemic areas[7].

Salmonellae reach the gallbladder through the blood stream and have been shown to have a tropism for the vesicular gallbladder wall.[5].In acute typhoid infections, colonisations of the gall bladder is rarely diagnosed but becomes apparent when features of acalculous cholecystitis develop.

The gallbladder acts as a unique replication niche for salmonellae which explains the high concentration of bacteria in infected gallbladders. Salmonella is known to undergo both extracellular replication in bile as well as intracellular replication in the epithelial cells of the gall bladder wall. This causes sloughing of infected cells, inflammation and tissue damage.[5] Intense inflammation of the gall bladder, coupled with infection with a virulent organism like Salmonellae in an immunocompromised individual lead to thrombosis of the cystic artery with trans mural necrosis and perforation[8].

Neimers described three forms of gallbladder perforation, free gallbladder perforation and generalized biliary peritonitis as type I, pericholecystic abscess and localized peritonitis as sub-acute or type II , and cholecystoenteric fistula as type III [9]. Gall bladder perforations at the fundus are more likely to end up with a type I gall bladder perforation whereas type II is associated with walling off of the site of perforation by omentum or intestines often when the disease is not limited to the fundus which our patient was afflicted with[10].

The patient had matted inflamed and oedematous bowel with free pus in the abdomen which was thought to either be due to a sealed perforation since she had been on antibiotics.[11] though it could have also been due to leakage of the pericholecystic abscess, there was no evidence of this at laparotomy. Previous reports have shown that complicated acalculous cholecystitis can occur in concordance with bowel complications though this was not the case in this patient.[12]

Indications for surgery/cholecystectomy in children with acute acalculous cholecystitis are complications like perforation, empyema and gangrene commonly seen in patients with systemic bacterial infections.[13]this was the treatment of choice in the patient who underwent a subtotal cholecystectomy. This procedure with non-closure of the cystic duct is associated with bile leak in up to $42 \%$ of the patients. [14]. Since there was no distal blockage of the bile duct, conservative management was sufficient in managing the patient. 
In conclusion, increased suspicion especially in populations at risk by attending physicians will enable use of available diagnostic tools like ultrasound scan for early diagnosis and better patient management.

Conflict of Interest : The authors declare that they have no conflicts of interest.

Informed Consent: Informed consent was obtained.

Funding : No funding was received for this study.

\section{Author contributions}

Author 1: Involved in data acquisition and drafting of the manuscript.

Author 2: Involved in data acquisition.

Author 3: Involved in drafting of the manuscript.

Author 4: Did the final review of the manuscript and gave approval for final copy for publication.

\section{References}

[1] Guidelines for the Management of Typhoid Fever 2011.

[2] Kabwama SN, Bulage L, Nsubuga F, Pande G, Oguttu DW, Mafigiri R, et al. A large and persistent outbreak of typhoid fever caused by consuming contaminated water and street-vended beverages: Kampala, Uganda, January - June 2015. BMC Public Health 2017;17:1-9. doi:10.1186/s12889-016-4002-0.

[3] Santisteban-ponce TJOJ. Theresa J. Ochoa * Javier Santisteban-Ponce 2019;1. doi:10.1016/B978-0-32337692-1.00111-8.

[4] Saxena V. Perforation of the gall bladder following typhoid fever - induced ileal perforation 2007:475-7.

[5] Menendez A, Arena ET, Guttman JA, Thorson L, Vallance BA, Vogl W, et al. Salmonella Infection of Gallbladder Epithelial Cells Drives Local Inflammation and Injury in a Model of Acute Typhoid Fever . J Infect Dis 2009;200:1703-13. doi:10.1086/646608.

[6] Gnassingbé K, Katakoa G, Kanassoua KK, Adabra K, Mama WA, Simlawo K, et al. Acute cholecystitis from typhic origin in children. African J Paediatr Surg 2013;10:108-11. doi:10.4103/0189-6725.115033.

[7] Mateen MA, Saleem S, Rao PC, Reddy PS, Reddy DN. Ultrasound in the diagnosis of Typhoid fever. Indian J Pediatr 2006;73:681-5. doi:10.1007/BF02898444.

[8] Sandeep K, Ashok P, Anwar A, Yadav AK, Sakhrani JK, Akhil K. Gall bladder perforation: an unusual presentation of enteric fever. J Pharm Biomed Sci 2015;5:408-14.

[9] Niemeier O. Acute free perforation of the Gall-bladder. Ann Surg 1934;99:922-44.

[10] Derici H, Kara C, Bozdag AD, Nazli O, Tansug T, Akca E, et al. Diagnosis and treatment of gallbladder perforation 2006;69:7832-6.

[11] Abdur-rahman OL, Adeniran OJ, Nasir AA. Outcome of Acalculous Cholecystitis From Typhoid in Nigerian Children 2009;101:717-9.

[12] Pandove PK, Moudgil A, Pandove M, Aggarwal K, Sharda D, Sharda VK. Case Report Multiple ileal perforations and concomitant cholecystitis with gall bladder gangrene as complication of typhoid fever 2014;7:10-2. doi:10.1093/jscr/rju070.

[13] Poddighe D, Sazonov V. Acute acalculous cholecystitis in children. World J Gastroenterol 2018;24:48709. doi:10.3748/wjg.v24.i43.4870.

[14] Elshaer M, Gravante G, Thomas K, Sorge R, Al-Hamali S, Ebdewi H. Subtotal cholecystectomy for "Difficult gallbladders": Systematic review and meta-analysis. JAMA Surg 2015;150:159-68. doi:10.1001/jamasurg.2014.1219. 